\title{
Effect of annealing temperature on the electrical properties of HfAlO thin films
}

\author{
Chun $\mathrm{Li}^{\mathrm{a}}$, Zhiwei He $\mathrm{b}^{\mathrm{*}}$ \\ Department of Applied Physics, China Agricultural University, Beijing 100083, China \\ ${ }^{a}$ lichunil@126.coml , ${ }^{b *}$ hezw@cau.edu.cn,
}

Keywords: High-K gate dielectrics, HfAIO, ALD, Electrical properties

Abstract. High-K gate dielectric HfAlO thin films with different temperature annealing treatment have been deposited on Si substrate by Atomic layer deposition (ALD). The electrical properties of Hf-films are analyzed by measurement of high frequency capacitance-voltage $(\mathrm{C}-\mathrm{V})$ and leakage current density-voltage (I-V) characteristics. The electrical measurement results indicate the decrease of equivalent oxide thickness (EOT) due to the great change of microstructure and densification after high temperature annealing and the increase of permittivity. But the interface state density increases. Moreover, the leakage current increases with the increase of annealing temperature. The HfAlO film annealed at $650^{\circ} \mathrm{C}$ has the best electrical parameters, such as dielectric constant, EOT and leakage current density determined through $\mathrm{CV}$ measurement were $23.5,0.84,6.8 \times 10^{-7} \mathrm{~mA}^{\cdot} \mathrm{cm}^{-2}$, respectively.

\section{Introduction}

Numerous materials with a higher permittivity than $\mathrm{SiO}_{2}$ have been studied as alternative gate oxide to overcome the limit of $\mathrm{SiO}_{2}$ in downscaling of complementary metal-oxide-semiconductor (CMOS) field effect transistor dimensions, such as $\mathrm{Al}_{2} \mathrm{O}_{3}, \mathrm{HfO}_{2}, \mathrm{TiO}_{2}, \mathrm{ZrO}_{2}$. Among the various potential high-k materials, $\mathrm{HfO}_{2}$ is considered as one of the most promising materials, because of its desirable properties including relatively high dielectrics constant, large band gap, excellent thermal and chemical stability. ${ }^{[1,2]}$ However, pure $\mathrm{HfO}_{2}$ film has its disadvantages, for instance, the density of active traps at and near the high-k dielectric/Si interface which is higher than the density of traps at $\mathrm{SiO}_{2} / \mathrm{Si}$ interface, which can act as significant scattering centers for carriers and increase and interface-state density. $\mathrm{HfO}_{2}$ is susceptible to crystallization after high temperature processing and has poor barrier to oxygen diffusion, and boron diffusion into the gate dielectric should be suppressed to maintain low equivalent oxide thickness (EOT) ${ }^{[3]}$ In order to solve these problems, $\mathrm{Al}_{2} \mathrm{O}_{3}$ was doped into the $\mathrm{HfO}_{2}$ film because of its large energy gap, good thermal stability, and high crystallization temperature. ${ }^{[4,5]}$

High-k gate dielectric HfAlO films have been deposited on Si substrate by atomic layer deposition (ALD) in this experiment. The electrical properties of the as-deposited HfAlO thin films and HfAlO films with different annealing temperatures have been investigated. High frequency capacitance-voltage $(\mathrm{C}-\mathrm{V})$ and the leakage current density-voltage $(\mathrm{J}-\mathrm{V})$ characteristics were analyzed systematically.

\section{Experimental}

The diagram of the experimental process and the MOS capacitor structure used in this paper were shown in Fig.1. The films were fabricated on 8-in, p-type Si substrates. First, p type Si (100) wafers were cleaned with $\mathrm{BOE}$ solution $\left(\mathrm{NH}_{4} \mathrm{~F}: \mathrm{HF}=6: 1\right)$ and washed in deionized water to remove organic contamination and the native oxide, then a device interface was prepared. The substrates were immediately loaded into the ALD reactor. TEMAH, $\mathrm{Al}\left(\mathrm{CH}_{3}\right)_{3}$ were used as the $\mathrm{HfO}_{2}$ and $\mathrm{Al}_{2} \mathrm{O}_{3}$ metal precursor respectively, and $\mathrm{H}_{2} \mathrm{O}$ as the oxidant. $\sim 3.85 \mathrm{~nm}$ HfTiOx films were deposited by ALD at $300^{\circ} \mathrm{C}$. The predicted growths per cycle of $\mathrm{HfO}_{2}$ and $\mathrm{Al}_{2} \mathrm{O}_{3}$ for this experiment are $0.75 \AA$ and $0.1 \AA$, respectively. Different cycles of $\mathrm{HfO}_{2}$ and $\mathrm{Al}_{2} \mathrm{O}_{3}$ were adopted to prepare the HfAlO film. After the ALD oxide layers deposition, metal-oxide-semiconductor (MOS) capacitors were formed with TiN 
film of $\sim 5 \mathrm{~nm}$ thickness as top electrode formed by ALD. W of $\sim 75 \mathrm{~nm}$ thickness was used to cap the reactive TiN metal electrode to prevent its subsequent oxidation on exposure to air. And the bottom electrodes $(\mathrm{Al})$ were deposited with the good ohmic contact. Post metallization annealing (PMA) with forming gas annealing were carried out in forming gas $\left(95 \% \mathrm{~N}_{2}+5 \% \mathrm{H}_{2}\right)$ at $450^{\circ} \mathrm{C}$ for $20 \mathrm{~min}$. After the fabrication process, the high frequency $\mathrm{C}-\mathrm{V}$ characteristics and the gate leakage currents of the MOS capacitors were measured at a frequency of $1 \mathrm{MHz}$ with Keithley 4200. The $\mathrm{C}-\mathrm{V}$ fitting was performed with QMCV simulation software developed by Berkeley University.

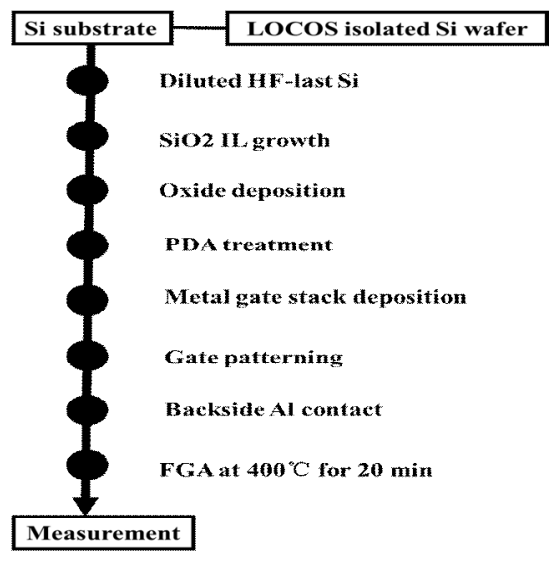

(a)

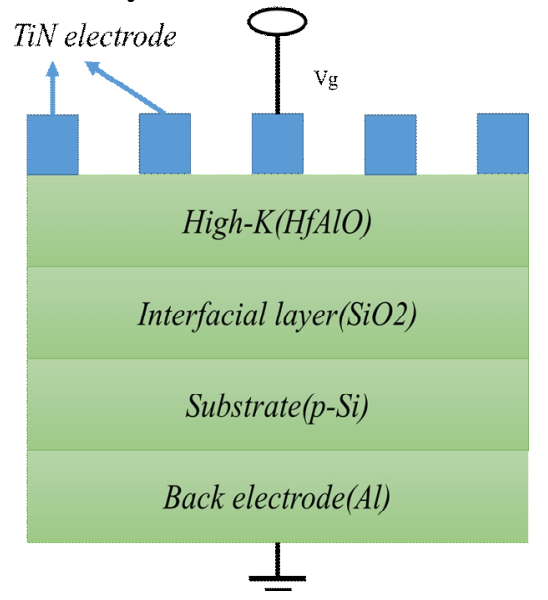

(b)

Fig 1 (a) Experimental process diagram ;(b)Schematic of structure of TiN/HfAlO/SiO2/p-Si MOS

\section{Results and Discussion}

To investigate the influence of doping $\mathrm{Al}$ on the electrical of $\mathrm{HfO}_{2}$ film, we fabricate capacitors with pure $\mathrm{HfO}_{2}$ film and 3.5\% Al-doped $\mathrm{HfO}_{2}$ film as the gate oxide, respectively. The films were annealed at $650^{\circ} \mathrm{C}, \mathrm{N}_{2}, 60 \mathrm{~s}$. The dependence of high-frequency $(1 \mathrm{MHz}) \mathrm{C}-\mathrm{V}$ characteristics on the annealing temperatures, swept from $0 \mathrm{~V}$ to $1.2 \mathrm{~V}$, is depicted in Fig 2. Electrons are tunneling from the substrate to the thin film. QMCV simulation software developed by Berkeley University is used to extract EOT and $\mathrm{V}_{\mathrm{FB}}$ from the $\mathrm{C}-\mathrm{V}$ data. Tab 1 shows the electrical parameters obtained through QMCV.

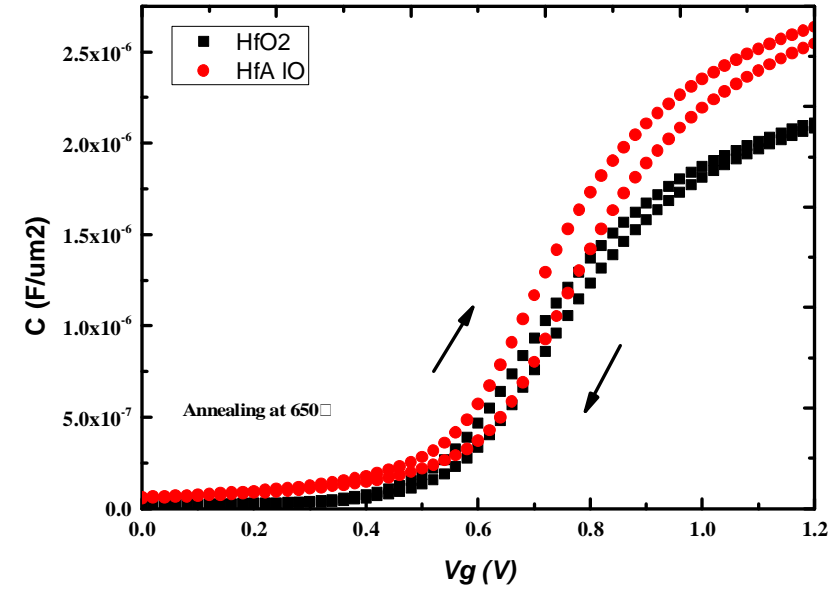

Figure 2 High frequency $\mathrm{C}-\mathrm{V}$ curve of $\mathrm{HfO} 2$ and $\mathrm{HfAlO}$

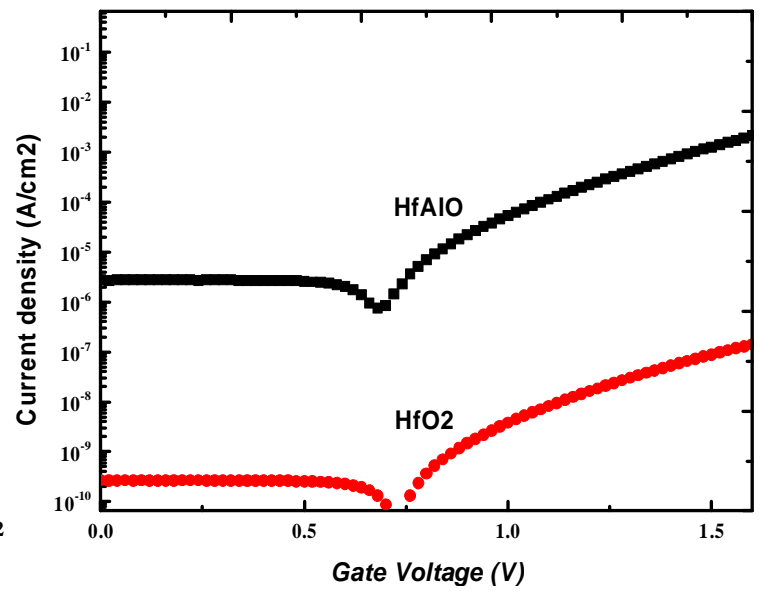

Figure $3 \mathrm{I}-\mathrm{V}$ curves of $\mathrm{HfO} 2$ film and $\mathrm{HfAlO}$ films

films with annealing at $650^{\circ} \mathrm{C}$

As shown in Fig 2, it can be seen that the equivalent oxide thickness (EOT) of HfAlO film is smaller than $\mathrm{HfO}_{2}$ film which due to the rate of oxygen diffusion of $\mathrm{Al}_{2} \mathrm{O}_{3}$ is far slow, and the growth of the interfacial layer with relative lower $\mathrm{K}$ can be slow down through doping $\mathrm{Al}$. The interfacial layer can reduce the accumulation capacitance $\left(\mathrm{C}_{\text {acc }}\right)$ density, so the $\mathrm{HfO}_{2}$ film has a smaller $\mathrm{C}_{\mathrm{acc}}$ which induce the relative dielectric constant $\mathrm{K}$ of $\mathrm{HfAlO}$ is larger than $\mathrm{HfO}_{2}$. However, the oxide trap charge density $\left(\mathrm{Q}_{\mathrm{m}}\right)$ 
of $\mathrm{HfAlO}$ is more than $\mathrm{HfO}_{2}, \mathrm{Q}_{\mathrm{m}}$ can be calculated from the equation $\mathrm{Q}_{\mathrm{m}}=\mathrm{C}_{\mathrm{acc}} \cdot \Delta \mathrm{V}_{\mathrm{FB}} / \mathrm{q}$, the result as shown in Tab $1, Q_{m}$ of HfAlO film is $9.6 \times 10^{11} \mathrm{~cm}^{-2}$. Since the HfAlO has a certain amount of Al-O or Hf-Al-O bond, these bonds has a better binding energy with oxygen located in the interface compared with Hf-O bond, inducing the formation of oxygen vacancy, the oxide trap charge density increase after oxygen vacancy trapping the charge .

Fig 3 is the I-V curve of $\mathrm{HfAlO}$ film and $\mathrm{HfO}_{2}$ film both are annealed at $650^{\circ} \mathrm{C}$. We can see that the leakage current density of $\mathrm{HfAlO}$ film is larger than $\mathrm{HfO}_{2}$ film more than one order of magnitude. As we all know that the coordination number of $\mathrm{Al}$ atomic is large than the $\mathrm{SiO}_{2}$, which induce the increase of dangling bond, is easy to break up, increasing the density of interface state.

To investigate the electrical properties of HfAlO thin films, capacitors with TiN electrodes with area of $100 \mu \mathrm{m} * 100 \mu \mathrm{m}$ were measured. The annealing temperature of the $\mathrm{HfAlO}$ films are $650^{\circ} \mathrm{C} 、 700^{\circ} \mathrm{C}$, $750^{\circ} \mathrm{C} 、 800^{\circ} \mathrm{C}$. As shown in Fig 4, comparing the annealing HfAlO films with as-deposition film, it is found that the $\mathrm{C}-\mathrm{V}$ curves are steeper in depletion layer, which indicate the interface state densities are lower. Besides, the accumulation capacitances $\left(\mathrm{C}_{\mathrm{acc}}\right)$ increase significantly. It is well know that the $\mathrm{C}_{\mathrm{ox}}$ is related to the interfacial layer, the application of post deposition annealing (PDA) may be attributed to the suppression of the growth of interfacial layer and improvement of interface quality. The equivalent oxide thickness (EOT) values of capacitors are shown in Tab 1. From Tab 1, it can be seen that the equivalent oxide thickness of samples after PDA are smaller than the as-deposition and the smallest EOT is $0.84 \mathrm{~nm}$ when annealing temperature is $650^{\circ} \mathrm{C}$. From the EOT, we can derive the dielectric constant $\mathrm{K}$ of HfAlO thin films through the equation ${ }^{[6]}: \mathrm{K}_{\text {high- } \mathrm{k}}=\mathrm{K}_{\mathrm{SiO} 2} \times \mathrm{T}_{\text {high- } \mathrm{k}} /\left(\mathrm{EOT}-\mathrm{T}_{\mathrm{SiO} 2}\right)$, The $\mathrm{T}_{\text {high-k }}$ and $\mathrm{T}_{\mathrm{SiO} 2}$ are the thickness of $\mathrm{HfAlO}$ thin films and $\mathrm{SiO}_{2}$ thin film respectively. The dielectric constants $(\mathrm{k})$ of samples are showed in Tab 1 . The sample after $650^{\circ} \mathrm{C}$ annealing has the highest dielectric constant, which reaches to about 23.5. The decrease of EOT and increase of dielectric constant $\mathrm{k}$ after annealing could be due to the great change of microstructure and densification of the films after high temperature annealing. $\mathrm{Al}$ atoms with small radius can diffuse into $\mathrm{HfO}_{2}$ during PDA, which benefits the formation of tetragonal phase $\mathrm{HfO}_{2}$ which exhibits high permittivity. ${ }^{[7,8]}$

Tab 1 The electrial parameters obtained through QMCV from C-V curve

\begin{tabular}{ccccc}
\hline $\begin{array}{c}\text { Electrical } \\
\text { parameter }\end{array}$ & As-deposited & $\begin{array}{c}\text { Annealed at } \\
650^{\circ} \mathrm{C}\end{array}$ & $\begin{array}{c}\text { Annealed at } \\
700^{\circ} \mathrm{C}\end{array}$ & $\begin{array}{c}\text { Annealed at } \\
750^{\circ} \mathrm{C}\end{array}$ \\
\hline $\mathrm{C}_{\mathrm{acc}}(\mathrm{pF} / \mathrm{cm} 2)$ & 218 & 258 & 230 & 223 \\
$\mathrm{~K}$ & 17.3 & 23.5 & 22.8 & 22.1 \\
$\mathrm{EOT}(\mathrm{nm})$ & 1.07 & 0.84 & 0.86 & 0.88 \\
$\mathrm{~V}_{\mathrm{FB}}(\mathrm{V})$ & 0.38 & 0.46 & 0.44 & 0.48 \\
$\Delta \mathrm{V}_{\mathrm{FB}}(\mathrm{mV})$ & 32.6 & 59.6 & 50.7 & 45.8 \\
$\mathrm{Q}_{\mathrm{m}}\left(\times 10^{11} \mathrm{~cm}^{-2}\right)$ & 4.4 & 9.6 & 7.3 & 6.4 \\
\hline
\end{tabular}

The PDA treatment has an effect on $\mathrm{V}_{\mathrm{FB}}$ that a positive shift can be seen compared with the sample without annealing. However, a negative $\mathrm{V}_{\mathrm{FB}}$ shift is observed while after $700^{\circ} \mathrm{C}$, which may be attribute to the oxygen vacancy generation caused by annealing. The value of $\mathrm{V}_{\mathrm{FB}}$ with PDA are larger than without PDA, indicate that the films after annealing contain more defects and traps which attributed to oxygen vacancies. ${ }^{[9]}$ It also can be seen clearly that as-deposition HfAlO thin films has smaller flat band voltage hysteresis $\left(\Delta \mathrm{V}_{\mathrm{FB}}\right)$ which indicate that the sample with PDA has larger border trapped oxide carge density.In brief, the interface quality is bader than that of as-deposition HfAlO thin film.

Fig 5 demonstrates the I-V characteristics of HfAlO gate dielectric capacitors. The leakage current density at the voltage of $\mathrm{V}_{\mathrm{FB}}+1 \mathrm{~V}$ of samples are $2.4 \times 10^{-7} \mathrm{~mA} \cdot \mathrm{cm}^{-2}, 6.8 \times 10^{-7} \mathrm{~mA} \cdot \mathrm{cm}^{-2} 、 9 \times 10^{-7} \mathrm{~mA} \cdot \mathrm{cm}^{-2}$, 
$11.8 \times 10^{-7} \mathrm{~mA} \cdot \mathrm{cm}^{-2} 、 12.2 \times 10^{-7} \mathrm{~mA} \cdot \mathrm{cm}^{-2}$, respectively. The as-deposition HfAlO thin film has the lowest leakage current density. The high annealing temperature could make films to produce crystals, which is a pathway to deliver the leakage current. Due to the interfacial layer between HfAlO films after annealing and substrate has more interface states, which have bad influence on the leakage current. Therefore, with the increase of annealing temperature, the leakage current densities increase obviously. The results show that $\mathrm{HfAlO}$ thin film with $650^{\circ} \mathrm{C}$ has the best electrical properties.
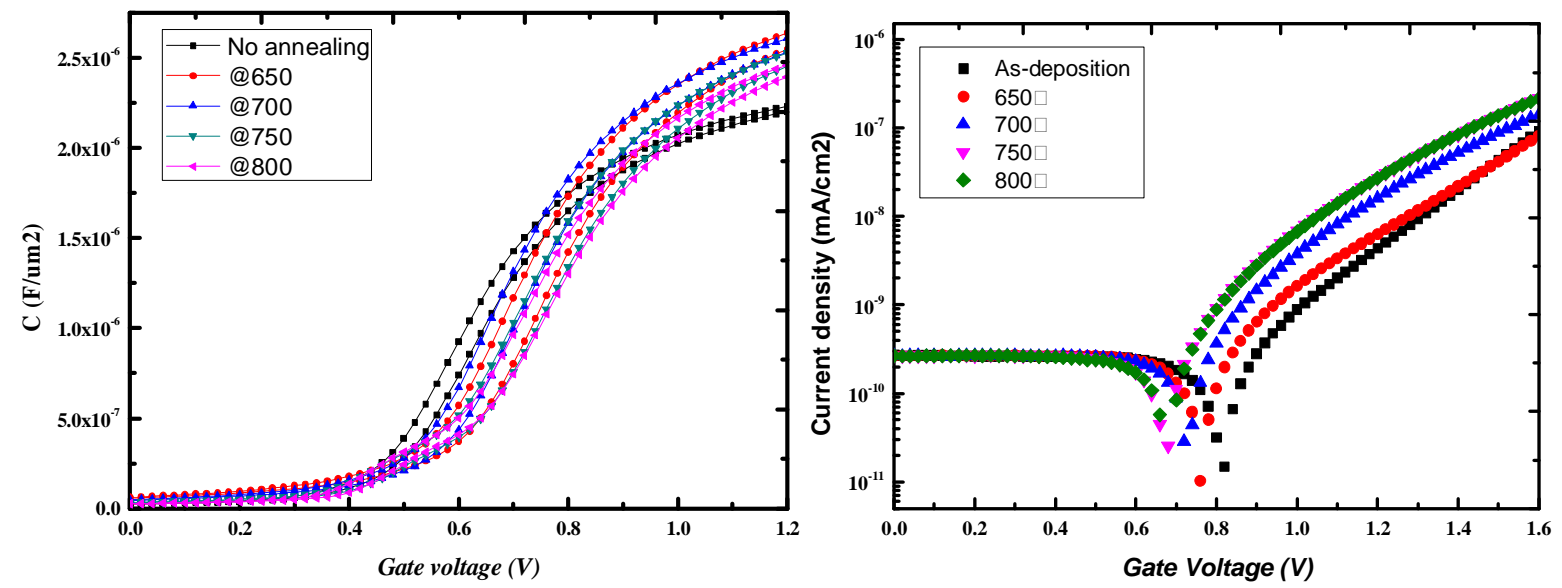

Fig 4 High frequency (1MHz) C-V characteristics of HfAlO Fig $5 \mathrm{I}-\mathrm{V}$ characteristics of HfAlO gate dielectric capacitors

\section{Conclusions}

In this work, $\sim 3.85 \mathrm{~nm} \mathrm{HfO}_{2}$ and $\mathrm{HfAlO}$ film annealed at $650^{\circ} \mathrm{C}$ were deposited by Atomic layer deposition (ALD), the HfAlO film showed a better electrical properties compared with $\mathrm{HfO}_{2}$ film. Then, we investigated the property of as-deposition HfAlO film and annealed HfAlO films with different annealing temperature were deposited by $\mathrm{ALD}$ at $300^{\circ} \mathrm{C}$. From the results, it can be seen that the increase of dielectric constant $\mathrm{k}$ and the decrease of EOT and leakage current density with the increase of annealing temperature. The film annealed at $650^{\circ} \mathrm{C}$ has a dielectric constant of 23.5 , a EOT of $0.84 \mathrm{~nm}$, and leakage current of $6.8 \times 10^{-7} \mathrm{~mA} \cdot \mathrm{cm}^{-2}$ at a gate bias of $\mathrm{V}_{\mathrm{g}}=\mathrm{V}_{\mathrm{FB}}+1 \mathrm{~V}$. The HfAlO film annealed at $650^{\circ} \mathrm{C}$ has the best electrical properties.

\section{Acknowledgment}

This work was supported by Central Education Foundation No. 2016LX002 and the Grant No. 51007092 of the National Natural Science Foundation of China, and Grant No. 708014 of Ministry of Education Train Foundation of China.

\section{References}

[1] J. Gao, G. He, B. Deng, D.Q. Xiao, M. Liu, P. Jin, C.Y. Zheng, Z.Q. Sun, J. Alloy. Compd. 662 (2016) 339.

[2] K.S. Agrawal, V.S. Patil, A.G. Khairnar, A.M. Mahajan, Applied Surface Science 364 (2016) 747.

[3] M. Liu, L.D. Zhang, G. He, X.J. Wang, M. Fang, Journal of Applied Physics 108 (2010) 024102.

[4] Y.M. Ding, D. Misra, Journal of Vacuum Science \& Technology B 33 (2015).

[5] D. Cao, X. Cheng, L. Zheng, D. Xu, Journal of Vacuum Science \& Technology B Microelectronics \& Nanometer Structures 33 (2015) 275.

[6] G.D. Wilk, R.M. Wallace, J.M. Anthony, Journal of Applied Physics 89 (2001) 5243. 
[7] C.K. Lee, E. Cho, H.S. Lee, C.S. Hwang, S. Han, Physical Review B Condensed Matter 78 (2008) 1436.

[8] P.K. Park, S.-W. Kang, Applied Physics Letters 89 (2006) 192905.

[9] J. Robertson, Solid-State Electronics 49 (2005) 283. 